\title{
Blackjack in the Kitchen: Understanding Online versus Casino Gambling
}

\author{
JUNE COTTE \\ KATHRYN A. LATOUR*
}

\begin{abstract}
About $\$ 10$ billion a year is spent by consumers worldwide on online gambling, and that number continues to grow. We present a qualitative, image-based study of 30 Las Vegas online and casino gamblers. By examining online gambling as a consumption experience, we examine what happens to consumption meaning as gambling moves away from a regulated physical space to an unregulated online space, one accessed from home. We explore the meaning of online gambling consumption to consumers and flesh out the social welfare implications of our findings.
\end{abstract}

$\mathrm{G}$ ambling, in various forms, exists within most human societies (D. Schwarz 2006). There has been massive growth in consumer spending on casino gambling over the past few decades. A study conducted by Price Waterhouse Coopers in 2006 predicted that global gambling revenue would rise by $8.8 \%$ annually from $\$ 82.2$ billion in 2005 to approximately $\$ 125$ billion by the end of the decade (Associated Press 2006). From 1992 to 2003, the U.S. casino industry saw its revenue more than double, from $\$ 10$ billion to over $\$ 27$ billion; consumers spent more money in casinos than they spent on movies or theme parks (American Gaming Association 2004).

As consumption of gambling has grown so too have concerns about the negative personal and societal outcomes of gambling, including pathological addiction and financial difficulties. Most concerns and virtually all empirical research have addressed the public consumption of gambling, mainly in casinos but also in public spaces like betting shops. How-

\footnotetext{
*June Cotte is the George and Mary Turnbull Faculty Fellow and associate professor of marketing at the Richard Ivey School of Business, University of Western Ontario, 1151 Richmond St. London, ON, N6A 3K7 (jcotte@ivey.ca). Kathryn A. LaTour is associate professor at the William F. Harrah College of Hotel Administration at the University of Nevada, Las Vegas, 4505 Maryland Parkway, Las Vegas, NV 89145 (kathryn.latour@unlv.edu). This research was funded by a grant to the second author from the Harrah College of Hotel Administration at the University of Nevada. The authors thank Remi Trudel, Jenni Denniston, Mark Lee, and Veronika Papyrina for research assistance. They would also like to thank Linda Price, Hope Schau, Glenn Christensen, and participants at the 2007 Consumer Culture Theory conference for challenging our thinking along the way. Finally, they also greatly appreciate Robin Coulter's valuable feedback throughout this project.
}

John Deighton served as editor and David Glen Mick served as associate editor for this article.

Electronically published September 23, 2008 ever, gambling is changing. There has been an increase in online gambling, with the concomitant movement of gambling into the home. Recent estimates of online gambling revenues range from $\$ 10$ billion to $\$ 12$ billion yearly (M. Schwartz 2006).

Although there is scant data, researchers have speculated that, as compared to casino gambling, the risk for addiction to online gambling is higher for several reasons. The software increases the speed of play, and the technology is now affordable, anonymous, and readily accessible (Griffiths 2002). Money wagered is often drawn from an online account, making it less likely that players notice when it is running low, and online gamblers tend to play alone, without friends looking out for them (Smith 2004). There are also models of consumer addiction (e.g., Hirschman 1992; O'Guinn and Faber 1989) that parallel the study of compulsive gambling (Griffiths 2002). For instance, Shaffer and Kidman (2003) show that there might be biological aspects leading to gambling addiction (such as a history of depression), psychological aspects leading to gambling addiction (e.g., low self-esteem), and social aspects leading to gambling addiction (gambling being a positive reinforcement, replacing social circles).

In our research we examine online gambling as contrasted with casino gambling. The theoretical significance of our research is our focus on differential meanings for the focal construct gambling. That is, studies of other consumption activities that are now available online do not assume that the construct's meaning changes because it is done at home. We argue herein that, although some experiential consumption can be done at home, it becomes a different consumption experience when it is done at home. Our work extends theory and research because we examine the well-studied phenomenon of casino gambling and challenge the idea that 
theories developed to explain that phenomenon can be applied in the online gambling realm.

Reviewing the literature, we concluded that researchers did not yet know answers to the following questions: How do gamblers experience online gambling? What does online gambling feel like, and how is it perceived? What happens to the experience of gambling when it moves online and becomes more private? Finally, what does that information tell us about the consumer welfare implications of this growing practice? A priori, we take no strong moralizing tone: the movement of gambling into the home may have consumer welfare-related advantages for some consumers (e.g., no worry of being robbed in a casino parking lot after a big win), whereas for others the effects may be more pernicious (e.g., children seeing gambling at home).

We begin with an examination of gambling as consumption, noting the omission of studies dealing with how consumers experience online gambling. We then present a qualitative study of 30 local Las Vegas gamblers, a sample whose readily available daily access to all forms of gambling allows us to compare and contrast online gambling to casino gambling. Using interviews centered on visual images, we study online gambling and casino gambling and juxtapose the two. We highlight the consumer welfare implications of our findings and then conclude with suggestions for further research.

\section{PRIOR PERSPECTIVES ON GAMBLING CONSUMPTION}

Researchers from sociology (Zola 1963), psychology (Walker 1992), economics (Grinols 2004), and leisure studies have examined gambling and how it relates to their disciplines. Researchers have studied the underlying motivations for gambling behavior; many have attempted to create a gambling theory and/or descriptions of gamblers. Although the gambling literature is vast, we briefly encapsulate the prior research on casino gambling before moving to the relatively scant literature on online gambling.

\section{Casino Gambling}

The term casino originally referred to a public hall for music and dancing, but by the second half of the nineteenth century the term had begun to refer to a collection of gambling rooms that were mainly on the Western frontier. The history of gambling in the United States includes periodic bouts of opposition on moral or religious grounds. Gambling was legalized in Nevada in 1931 as a means of luring tourists to the Hoover Dam. Las Vegas initially attracted, and was funded by, organized crime. In the 1950s it was the government who opposed casino gambling. Things have changed: resort casinos are regulated, they are often funded by Wall Street, and they have very little resemblance to the tavern-style roadhouses of the past, which primarily offered dice and card games. Casino gambling is now legal in all but two U.S. states, and the mega resorts of Las Vegas also offer high-end dining, shopping, and entertainment as supplements to gambling.
Cotte (1997) categorized gambling motives into three general groups: economic, symbolic, and hedonic. With regard to the former, researchers have theorized that gamblers are in it for the money, that economic motives are primary for many gamblers (e.g., Fisher 1993). Others suggest that money simply makes the gambling more important, risky, and involving (Herman 1976). Gambling also may confer a symbolic sense of control for those in society who lack control (usually defined as lower socioeconomic status groups; Zola 1963). In addition, performing under pressure at a casino can be interpreted as a symbolic gesture of risktaking (Cotte 1997). Researchers have also interpreted gambling as self-esteem enhancement, suggesting that it allows gamblers to create a more favorable, fantasy-based selfimage (Loroz 2004).

We suspected that not all of the established theories about casino gambling (particularly concerning its meanings) would hold for at-home gambling. After all, the prior research on gambling focused on public corporeal consumption of these games. Conceptually, there are reasons to believe that these theories will not hold, primarily because of the elemental differences between online and real-world interactions and communication.

What researchers know is that online communication differs from face-to-face communication (Flaherty, Pearce, and Rubin 1998; McKenna and Bargh 2000) partly because it is impossible in online communication to properly transmit social context cues such as nonverbal behavior (Sproull and Kiesler 1986). While a lack of social cues has been shown to result in uninhibited or antisocial behavior, it might also lead to status equalization as interpersonal status information can be left out (Sproull and Kiesler 1986; Straus 1997). Indeed, researchers have argued that we do not yet know how, or if, social norms work in the online social environment (Mantovani 2001; Spears and Lea 1992). We do know that the anonymity possible during online interactions can have both positive and negative effects on behavior (Moon 2000; Schau and Gilly 2003). So it is relatively clear that at-home online interactions may be very different from casino gambling. The social science community simply does not know very much about the consumption experience of online gambling and how it differs as a consumption experience. What we do know, we review below.

\section{Online Gambling Consumption}

In 1994 the Antiguan government passed a law that allowed online casinos to be established within its borders. Intercasino was the first online casino to accept real money wagers, and their revenue reports sparked great interest. The growth of online gambling has been significant, but because of the nature of play and the fact that online betting is technically illegal or in legal limbo in Canada and the United States, tracking the exact number of players, revenues, and wagers is difficult. Although estimates vary, the amount of money spent on online gambling is massive, about $\$ 7.5$ billion in 2004 (Stutz 2005). Growth can occur quickly because online gambling sites do not have to pay for the many 
expenses casinos do, including free alcoholic beverages and other perks for players, property taxes, and employees. As a result, online profit margins can be as high as 60\% (M. Schwartz 2006). Most casino games are available online, as are virtual slot machines. Table games like roulette, blackjack, and craps are all available online, but the most popular game online seems to be poker. The number of poker sites on the Internet grew from 30 in 2002 to over 400 in 2006 (M. Schwartz 2006). Web sites are getting increasingly sophisticated in their look and feel, and many offer sounds of chips hitting a table, roulette wheels spinning, or cards being dealt. An online player can experience real-time chat with other players and can choose virtual tables based on who is playing there.

Much of what we know about online gamblers is primarily descriptive in nature. At least one study has examined the increased tendency for Internet-based gambling to become addictive (King and Barak 1999), and online gamblers are more likely to be clinically problematic or pathological gamblers than casino gamblers (Ladd and Petry 2002). Internet gamblers are less educated than the Internet population as a whole and women outnumber men. Web users making less than $\$ 25,000$ a year are about $11 \%$ of the Internet population but about $15 \%$ of the users of online gambling, and the average online gambler is younger than the average Internet user (Ladd and Petry 2002; Woodruff and Gregory 2005). In a recent survey, $10 \%$ of survey respondents who gamble online did so for the first time before they were the age of 10 , and this gambling was often paid for by a family member (Derevensky and Gupta 2007). In sum, the extant research is mainly a collection of survey-based demographic studies, or objective assessments of technological differences, with extrapolations of possible implications for addiction. But none of these researchers focus on the meaning of online gambling to participants, to which we now turn.

\section{RESEARCH METHOD AND ANALYSIS}

\section{Method}

The authors conducted depth interviews with 30 local gamblers of Las Vegas, Nevada, using visual images and, ultimately, collages that the participants created (Zaltman 1997; Zaltman and Coulter 1995). This method, using pictures to probe for an individual's metaphorical thinking about a subject, is based on the premise that all thoughts are image based (Damasio 1994). Focused on unearthing the content of an individual's mind, this method assumes that much of this content is nonconscious and based in images, not words (Zaltman 1997; Zaltman and Coulter 1995). When contacted initially by phone, about 1 week ahead of the interview, participants were asked to come to the interview with five to eight images of what "gambling means to you." Images that the participants brought in were from magazines, newspapers, and, in some cases, their personal photo albums or scrapbooks.

The interview technique we used helps interviewers delve into the metaphors that participants use to represent the meanings of gambling, either explicitly to others or implicitly to themselves (Coulter and Zaltman 2000; Lakoff and Johnson 1980). To elicit metaphorical language, we included projective techniques and sensory probes, and we organized interviews around the participants' images. This array of techniques surfaces more than simple cognitions, also capturing emotions, attitudes, goals, values, and the sensory aspects of gambling (Christensen and Olson 2002). One main difference between this image-based interview and phenomenological interviews is that we begin with higherorder constructs conveyed through the metaphors and images and then proceed to particular experiences. Phenomenological interviews generally elicit experiences, and then researchers interpret meanings and etic constructs from those particulars.

We first asked participants to tell us their stories about the images they had collected. Next, we probed for missing images, pictures that they would have liked to have brought but could not find. Participants were encouraged to talk about how the images were different or similar, and we probed for higher-level constructs that participants were using to discuss what gambling means to them. The images they had brought or had wanted to find were the focus of most of our probing. We probed up, asking questions such as "How/What does gambling add to your life?" We also probed down, asking questions such as "What particular experience led to that?" Sensory data were collected next: participants were asked to talk about the sense aspects of gambling, including sounds and smells, and this allowed for further sensory probing (e.g., "What does gambling sound like?"). Another projective technique we used was to have participants describe the personalities of slot machine gamblers, casino table gamblers, and online gamblers, and then to describe what these three personalities might be like and how they might interact with one another. Finally, participants created a summary image by aligning their pictures on a background, discussing as they did so why certain images were given preeminence.

The interviews were audiotaped and transcribed verbatim. Some portions of these interviews, especially when participants were arranging the visual stimuli they had selected, were also videotaped. The data include 900 pages of verbatim transcribed interview texts and 150 images, along with videos of portions of some of the interviews. Each participant was paid $\$ 100$.

\section{Sample}

We advertised in a local newspaper for self-defined regular gamblers. The two authors of this article conducted 30 interviews: 10 with online gamblers and 20 with casino gamblers. We recruited both casino chance game players (e.g., slots) and casino skill game players (e.g., poker) deliberately to maximize the variation in types of gamblers we spoke with. Although a couple of the online gamblers had tried online slot machine games, the online gamblers mainly played skill games like poker and blackjack online, while the casino sample group included both slot machine 
players and skill game players. While there are overlaps-for example, a woman who gambles on the Internet from home every day may take out-of-town guests to a major Las Vegas Strip casino-our sample participants were easily able to label themselves as predominately casino or online gamblers, and we allowed them to so self-classify. Sampling in Las Vegas allowed us to find a theoretically interesting group: in our sample are gamblers who now are primarily online gamblers but who were once casino gamblers. Thus, we can examine the differences between online gambling and casino gambling among those who have shifted their consumption from one to the other.

All participants were regular gamblers, by their own definition, although the frequencies of gambling consumption varied dramatically - from every day to once a month. We used purposeful sampling, and we tried to interview gamblers who spent $90 \%$ or more of their time gambling on one of the two types of gambling we were interested in: casino or online gambling. This was mainly a successful recruitment strategy, although some online gamblers still occasionally visited a casino, as discussed above. None of the participants self-defined themselves as professional or problem/addicted gamblers, although as one can observe from table 1, gambling consumption is a major part of most participants' lives. The ages of the participants ranged from
23 to 77. One characteristic is apparent from table 1: participants who were mainly online gamblers self-reported spending more time gambling than did casino gamblers.

\section{Analysis}

Our approach to the data is grounded in the procedures for rigorous interpretive analysis, including individual analysis, many iterations, and part-to-whole comparisons (Spiggle 1994; Thompson 1997; Thompson, Locander, and Pollio 1990). Both authors individually analyzed the mass of data, both text and images. We discussed emerging interpretations, challenged each other, and ultimately jointly created the interpretations. We strove to present both the experience of gambling as it is lived by our participants-as they see it-but also to inject some of the reality of the social consequences of their choices and behaviors. That is, we openly state that our voice (the voice of the researchers) is here; our analysis does make some etic-level comments on the emic words of our participants. As an example, if a participant focuses solely on the benefits of gambling, we may make note of some obvious disadvantages we see for that participant. When we do this, we believe that the shift from the emic level to the etic level is clear in our description.

TABLE 1

PARTICIPANT PROFILES

\begin{tabular}{|c|c|c|c|c|}
\hline Name & Age & Gender & Type of gambler & Frequency of gambling \\
\hline Alice & 58 & Female & Online & Every day, 3-4 hours \\
\hline Donna & 53 & Female & Online & 2-3 nights per week \\
\hline Danny & 54 & Male & Online & 20 hours/week \\
\hline $\mathrm{Jim}$ & 55 & Male & Online & Every night \\
\hline Cleo & 50 & Female & Online & Every day \\
\hline Jessica & 54 & Female & Online & Twice a week, 6 hours each time \\
\hline Manny & 77 & Male & Online & Daily \\
\hline Brittany & 23 & Female & Online & 3 days per week \\
\hline Tim & 22 & Male & Online & Almost daily \\
\hline Allen & 74 & Male & Casino & 3 times per week \\
\hline Alexandra & 27 & Female & Casino & $1-2$ times per month \\
\hline Belinda & 41 & Female & Casino & $2-3$ times per month \\
\hline Connie & 27 & Female & Casino & Twice per week \\
\hline Fred & 44 & Male & Casino & Once a week \\
\hline Greg & 57 & Male & Casino & Every day \\
\hline Jill & 70 & Female & Casino & 3-4 times per month \\
\hline Kristine & 57 & Female & Casino & Once a week \\
\hline Larry & 64 & Male & Casino & $1-2$ times per week \\
\hline Liam & 48 & Male & Casino & $1-2$ times per month \\
\hline Logan & 58 & Male & Casino & 5 days per week \\
\hline Lorraine & 35 & Female & Casino & $1-2$ times per week \\
\hline Matt & 51 & Male & Casino & 1-2 times per week \\
\hline Melanie & 37 & Female & Casino & Once a week \\
\hline Paul & 23 & Male & Casino & Twice per week \\
\hline Rebecca & 68 & Female & Casino & 3-4 times per week \\
\hline Sam & 32 & Male & Casino & Every weekend \\
\hline Sarah & 48 & Female & Casino & Twice per week \\
\hline Shelley & 32 & Female & Casino & Once per month \\
\hline
\end{tabular}

NOTE.-Frequency of gambling is described using the participants' own wording. 


\section{FINDINGS}

In our presentation, we will move from consumer reactions to the contextual differences between online and casino gambling to a discussion of the change in meaning as gambling moves from the casino into the home. We begin with reactions to contextual differences between in-home and casino gambling: perceptions, feelings, and experiences, primarily presented as thick, emic-level descriptions of various recalled experiences (as in Samantha's case study in Thompson et al. 1990). After this section, we build up three thematic dimensions that allow us to clearly outline the meaning changes that occur as gambling moves from the casino to the home.

\section{Consumer Reactions to Contextual Differences: Casino versus Online Gambling}

Perceptions. One important way in which online and casino gambling differ is how the context is perceived by gamblers. Two major differences are perceptions of social connectedness and perceptions of anonymity. First, we address social connectedness. For casino gamblers, gambling provides a perceived social connection with unknown others, the public, in a sense of shared fates and temporary community. Online gamblers, on the contrary, perceive a lack of social connections in the online realm. As we will discuss, these perceptual differences are seen by each group as positive aspects of their chosen gambling form.

Casino gamblers were rather negative regarding online gambling, primarily because they perceive a lack of desired social interaction. The importance of social connection to casino gamblers becomes clear as they describe online gambling. Alexandra was perhaps the most negative in her description and her perception of online gambling's lack of social connection:

I picture somebody that's smelly and stinky and hasn't taken a shower in a week and blah, nasty. Probably like some IT computer nerd, geek guy that can work out of his house. (Alexandra, 27, casino)

Some of the casino gamblers had tried gambling online but had decided that it was not for them: gambling was something to be done socially, in the casino.

And just being around the people . . . and it's just not the same at home. Sitting in your underwear and . . . no, no, in your pajamas with your bunny slippers on, and it's just not the same. (Melanie, 37, casino)

Casino gamblers perceive online gambling as bereft of social connections, which was pivotal to the enjoyment of gambling for them. The online gamblers also perceive this lack of social connectedness in virtual gambling. But for them this aspect is positive: it is one crucial reason the online gamblers give for their choice to gamble at home. They choose the online environment because of the lack of social connections. Clearly, Jessica avoids connections:

Online, you don't have to put up with these people. . . . In a land casino, the main interest is not, I don't think it's the gambling; it's the people around you. [Online] you can be as antisocial as you want to be because there's nobody to talk to there anyway. And to be perfectly honest, people bug me a lot. I just, sometimes people get on my nerves so bad. Uh, and I don't have to put up with that online. (Jessica, 54, online)

In Jessica's summary image, there are few people and those people pictured are by themselves. Brittany, another online gambler, chose a picture of random people to describe what she avoided when she was online (see fig. 1). Although Jessica rarely goes to a casino, when speaking about the occasions when she does, we can see that, despite her antisocial, anticasino view, there is still a social connection need not met for her in the online environment:

I go there [casino] not expecting to win anything. I go there mainly just for a need to feel in contact. And sometimes you just have to have that human contact. (Jessica, 54, online)

Clearly, gamblers perceive social connectedness as an important difference: the casino is a social connectedness site, while online Web sites are largely devoid of social connectedness.

A second important perceptual difference between the online and casino gambling contexts is perceptions of anonymity. Online gamblers report that a benefit of online gambling is its anonymity. Interestingly, when asked to describe the personalities of casino gamblers, most online gamblers had a clear image in their mind. A casino slot machine player was seen as being an older female who is overweight and needy. A casino table game gambler was described as male and outgoing. But when asked to describe other online gamblers, online gamblers themselves could not say anything concrete:

Faceless, can't give a personality description . . . never see them. (Jessica, 54, online)

You don't know those people. So they're just a name, an ID. (Manny, 77, online)

They don't give out too much information on people that you're playing with. . . . Don't get to see who that person is, how they act. (Brittany, 23, online)

Because players can disguise almost every aspect of their true identity, they can create a new identity, gender, age, or any other aspect of an entirely new persona, as can all the other players. One benefit of this perception of anonymity is that online players often think about the nameless others online in ways that fit the player's own desires. Donna looks at the icons and imagines the exotic locales of the players 
FIGURE 1

BRITTANY'S SUMMARY IMAGE

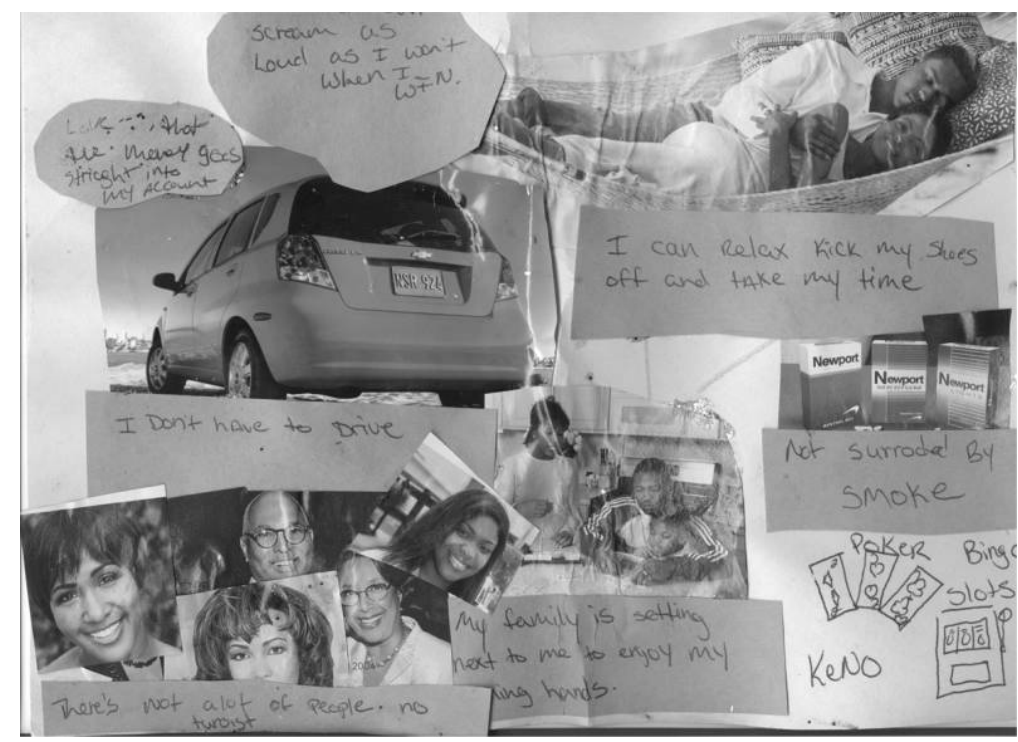

she is playing against. Mike assumes or pretends that the players online are just like himself and that he is playing with comrades. The ability to pretend to be someone else online influences more than just the avatar chosen; it extends to the type of behavior these gamblers describe. Online gamblers perceive no such anonymity in a casino, and they report that they gamble differently there as a result. Danny, an online poker player, says he plays much more aggressively online than in the casino. Brittany, whose favorite online game is poker, is afraid to play poker at a casino as she is not confident enough without the perception of anonymity that she perceives exists online.

The perceived anonymity of the online environment equalizes gamblers, so that low rollers and high rollers are treated equally. In contrast, in a casino more experienced gamblers who bet larger amounts are treated specially, and some gamblers go to the casino seeking such ego gratification. Greg is a casino table gambler who defines himself by his gambling prowess, and he has a need for social recognition that only the casino environment can provide:

And I don't think there's anybody that can beat me. . . . So that I know what I'm doing. And that's the challenge. I just love being able to walk out of there and say, "I' $m$ better than you guys." 'Cause gambling to me just reinforces my whole life. It's, it's something I have to win at. I have to be good at what I do and I've proved to other people I can do it. And proved to the world. (Greg, 57, casino)

For Greg, and several other casino gamblers, the perceived social visibility in the casino is important to his experience, and this could not be replaced by a perception of anonymity online.
Feelings. A second difference between casino and online gambling is the extent of feelings and emotions each engenders. Online gambling is simply not as vividly experienced as casino gambling. Our data show that the casino experience still continues to be demarcated from the routine by heightened expectation, preparation, and anticipatory excitement; these result in high arousal emotions like exhilaration and celebration. But while occasionally an online player might feel excited (e.g., by winning a poker tournament), the home environment results in a more mundane experience that feels comfortable and safe.

In terms of feelings, casino (but not online) gambling looks very much like the cycle of consumer desire outlined by Belk, Ger, and Askegaard (2003). This cycle of desire begins with self-seductive imagination and active cultivation of desire, followed by the acquisition of the desire, followed by wanting to return and reexperience the object of desire (Belk et al. 2003). First, there is an anticipatory phase, followed by ideally winning/celebrating, and then the reformulation of desire, the hope of winning more in the future. As Tim discusses his summary image (see fig. 2) he explains:

A picture here of a football player getting fired up for the big game, you know his anticipation is giving him an adrenalin rush. That's me before the casino. This guy jumping up and down in the air, you know. He's excited. . . . It's exciting, you know, being inside the casino with the bells and whistles and chips flying in the air. And then ideally at the end of the day maybe you won a lot of money, and this is you celebrating your win, which is another adrenalin rush, and then [after] this is me relaxing in a Sports Book, just enjoying my time with my friends. (Tim, 22, online) 
FIGURE 2

TIM'S SUMMARY IMAGE

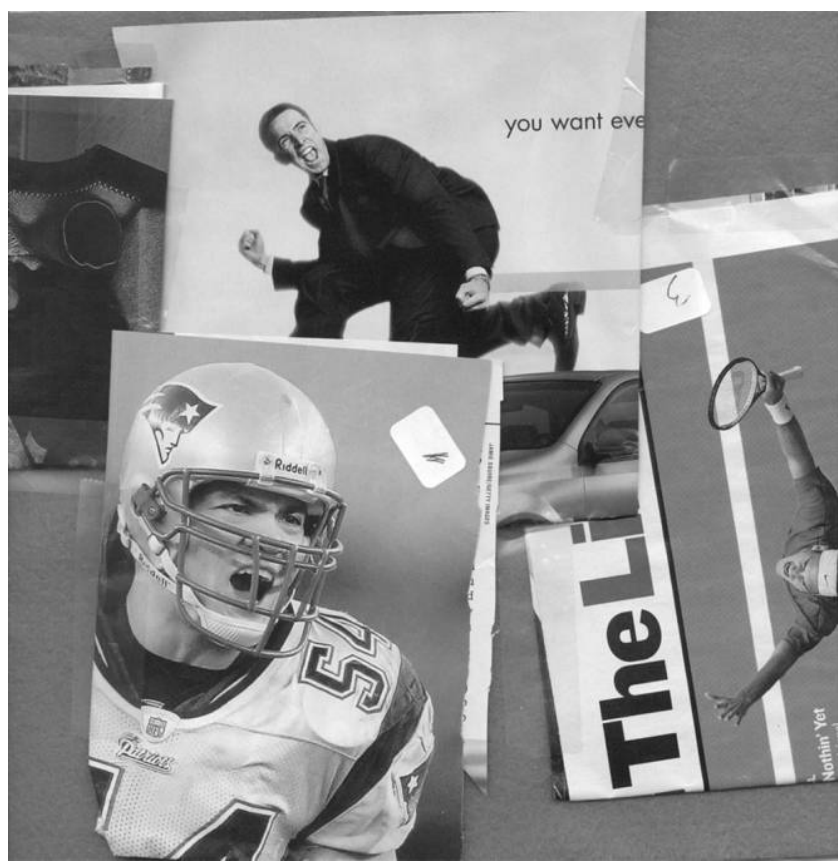

This intense and ongoing cycle is what helps casino gamblers reignite their desire. In contrast, our data suggest that online gamblers do not go through the same level of emotional preparation as they get themselves ready to play online. That is, they do not ignite a major "fire of desire" like the casino participants do. We believe that this difference contributes to a muted reaction to the outcomes of online gambling. Indeed, rather than discussing online gambling in highly charged emotional language, online participants describe it in rather mundane ways, likening the feeling to other passive behaviors, as Jessica does:

You have a longer period of time there that you don't sit around watching the same old TV shows or reading the same old books. It's just a diversion. . . . [Later] You can't get too excited about winning something, but you can't get too excited about losing something either. (Jessica, 54, online)

Online gamblers are more detached during online gambling consumption; they do not experience the intense highs and lows as they did (or others do) in the casino. In fact, several participants found the casino environment too exciting, like a rollercoaster:

I'm getting more hyped up [in a casino]. . . . Cause it is just up and down, up and down. (Jim, 55, online)

The rollercoaster metaphor is interesting as it implies a physicality to the casino experience, whereby the environ- mental stimulation leads to highs and lows that can take one's breath away. Danny, an online gambler who also occasionally plays in the casinos, mentioned feeling exhilaration when casino gambling. But after describing the exhilarating feeling of winning, when asked how often he feels that when gambling online, he reflected and replied: "Not very often." Later, he admits that, most of the time while he is online, he does not feel much:

So then you are sort of neutral. You don't have much to be real elated about, but you don't have much to be disappointed about and if, and you're sorta just floating around the middle. (Danny, 54, online)

Another online gambler, Mike, also admitted that he got a little bored online; he looked at the images he brought in and said: "Nothing looks very exciting here." (See his collage, fig. 3, where he chose the sunset image to represent the serenity he feels online.) He gets a more intense feeling when he is either winning or losing big, but most of the time he is "in the middle":

There's no frustration. You win some, you're losing some. It's very boring. . . . I tend to play longer when I'm either way ahead or way behind. (Mike, 55, online)

Indeed, a sort of calm complacency appears to settle on online gamblers. Manny mentions that he is more alert in the casino but that online he is more laid back:

\footnotetext{
You can gamble [online], and, and, you know, it's a pastime ... versus in the casino there is no such thing . . . so you gotta be on your toes more. (Manny, 77, online)
}

In addition to feeling less online than in the casino, our online players also reported feeling different emotions, such as safety and comfort, due to being in their own home. Donna feels safer at home "because of all the freaks out there." Brittany feels safer winning online than in the casino because she doesn't have to worry about someone following her back to her car and robbing her. Jessica notes how being at home allows her to feel comfortable and relaxed. Several others noted that they are often in their pajamas when they are gambling online.

Much better at my home because I can sit in my pajamas and cuddle up on my chair and just shut out everything around me. (Jessica, 54, online)

The comfortable style of gambling that results from feeling relaxed and playing in one's pajamas appears to circumvent the heightened self-awareness and self-monitoring that casino gambling appears to create. In fact, when casino gamblers were asked to describe online gamblers, several negatively suggested that they "pictured them in their dirty pajamas," as if that were an inappropriate uniform for gambling.

Sensory Experiences. Another difference between the online gambling and casino gambling contexts is sensory 


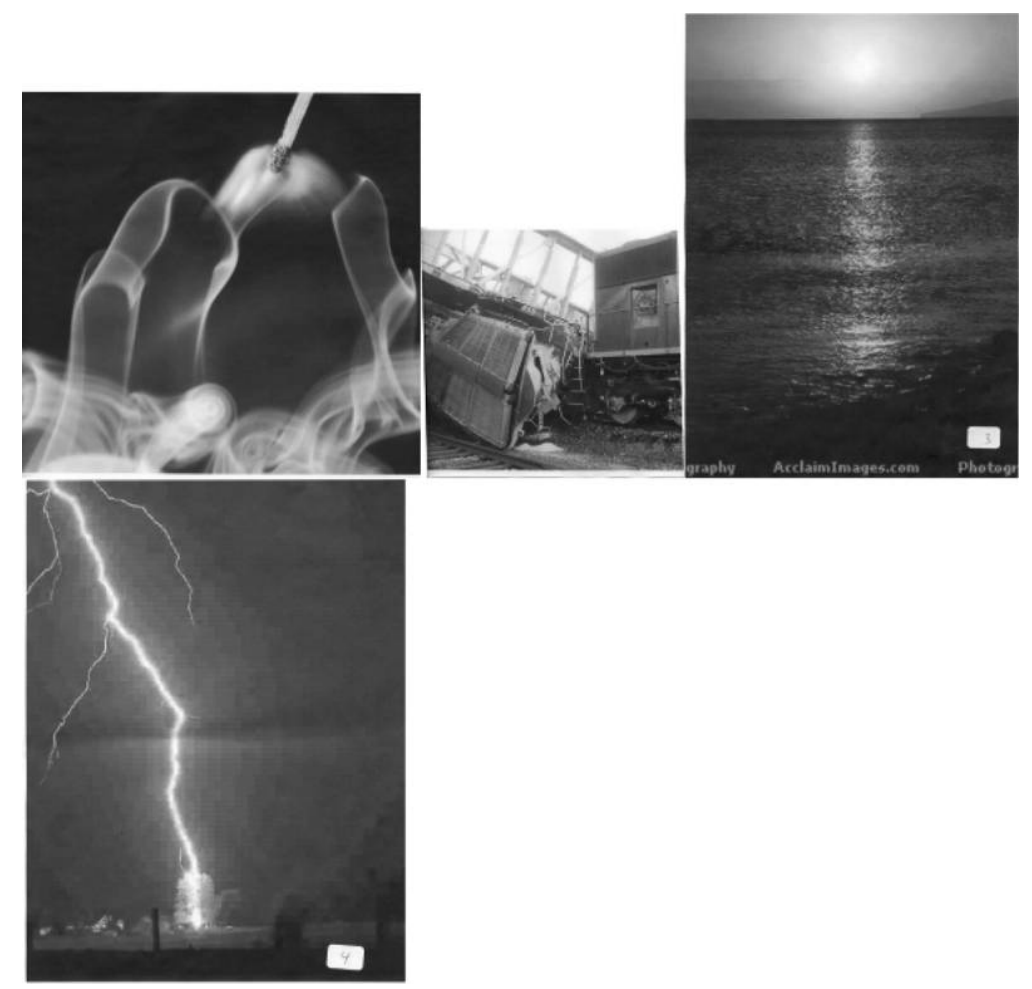

experiences, particularly haptic (touch) stimulation. Although online gambling Web sites have added sounds of casino gambling, including cards shuffling, wheels spinning, and chips hitting the table, most online gamblers report that online gambling lacks the sensory stimulation that they get in the casino. Our online gamblers have either the TV or the radio on for background noise, and they are in the same context in which they conduct their home activities. Casino gambler Herb remarked about the online gambling environment:

Okay, because the only thing that changes when I gamble online is my computer screen. Everything else in my office stays exactly the same. Whereas when I go [casino] gambling, there's always something, whether it's even a peculiar person or just, you know, all the different things that are buzzing and blinging. (Herb, 42, casino)

There is a lack of smells (which is generally positive, as casino smells are inevitably negative because of smoking), a lack of sights (people, lights), and a lack of touch. The touch stimulation can be further unpacked into touching the accoutrements of gambling (chips, money, cards) and the touch of other people. While the latter is related to social connection, it is also an unusual sensory phenomenon.

Sometimes the floor people will come up and touch me, or ask how you doing? Put their hand on my shoulders, rub my shoulders for good luck. You ask them for change, you know, they'll rub it on them for good luck. That's the silly things that they do but that's what makes me feel rich, it makes me feel good. (Lorraine, 35, casino)

This feeling good as a result of being touched by the casino employee is consistent with Hornik (1992), where customers felt better about the establishment and employees if they were touched unobtrusively. In addition to being touched by people, there is the sense of touch evoked by physically handling the chips and the money. Both Cleo and Tim identify this difference between casino and online gambling:

[Online] I'm not physically handling the chips, which, I mean handling the chips that, that's money and that, like when I'm playing Blackjack that's a very nice sensation, to fondle the chips. (Cleo, 50, online)

It's not the same [online], they're counting out a hundred or a thousand dollars in front of your face. That's a little more exciting. I won like a thousand dollar tournament. And I mean it's digital so it's like, it's not, no it's not the same. (Tim, 22 , online)

Having explored the perceptions, feelings, and senses resulting from the differing contexts of traditional and online 
casinos, we now move to a discussion of the changes in the meaning of gambling as it moves into the home. We present this discussion organized around three main dimensions of meaning. These are more abstract, etic-level interpretations gleaned from our within- and across-participant analysis, and they build on the contextual differences between online and traditional casinos.

\section{The Meaning of Gambling as It Moves into the Home}

From out of Control to in Control. By control we imply the need for control over one's life and environment. Our data suggest that casino gamblers appear to relish being out of control, while the online gamblers we spoke to believe that they have more control over their gambling outcomes. Belinda, one of our casino gamblers, describes her life outside of gambling as very structured and ordered, and she relishes giving up control to chance while in the casino:

I take things very seriously. I'm a thinker. I analyze things. .. . . [In my life] I'm always in control. Always in control. I get a little bit more out of control when I'm playing in the casino. And I kind of like that out of control feeling. I kind of like to not be so on top of everything, and so in charge of everything. (Belinda, 41, casino)

With all gambles, luck plays a more or less central element of the outcome. That is, while in some games, like poker, skill also plays a role, gambling is a gamble by definition because of the element of chance. Gamblers do not control the outcome of a gambling game; they only control their participation in it. While casino gambling participants told us that being out of control is one of the appeals of casino gambling, our data suggest that the experience of being at home leads many online gamblers to feel an illusionary sense of control. Online gamblers often speak as though they are in control of the outcome. Danny (50, online), who spends about 20 hours a week on online gambling, describes a picture of a rider on a horse:

Danny: Well, I see that as being in charge and being in control. . . He's got the reins, and he's controlling the situation.

Interviewer: And how does that relate to your feelings about online poker?

Danny: You want to be in charge, have command over the table.

Online gamblers felt that they had better control over their finances when they wagered online versus in the casino, often as a result of the contextual differences we outlined earlier. For example, Cleo mentioned that, lacking the physical sensation of holding the chips online, she was "less caught up in it" and could "sit back and think a bit more" about her gambles than if she were in a casino. Several of our online gambling participants mentioned that Web sites allow the gambler to set limits and have a cooling-off period before more money is allowed to be spent. All of these facets of Web site design created the impression, for these gamblers, that they had more control online than they did in a casino environment.

Because, gambling in a casino, if you lose your money, it takes you about two seconds to go and get some more. . . . If you're gambling online, they have a limit to how much you are going to be able to lose to begin with. It's harder to get a deposit in there. There's a waiting period between the time you do a deposit and the time your money actually goes in your account. So you have that cooling off period there. . . . Sometimes during that cooling off period, you think twice about it. And you can go, "No, I can't afford that. I better stop." (Jessica, 54, online)

Jessica thinks that these limits are necessary, and she does not think that gamblers in a casino can do an adequate job setting their own limits, but she believes that the online environment helps gamblers, including herself, stay in control. In her summary image, she juxtaposed a picture of a person hanging over the edge of a skyscraper beam into space with a picture of someone exercising vigorously. These images represent the lack of control that she felt when casino gambling and the control that she feels while gambling online, respectively.

While an out-of-control feeling can be experienced from time to time by all gambling participants in that they can all describe the moment when they place a bet or spin the wheel, relinquish control, and leave it to fate, for casino gamblers this is pleasurable and part of the meaning that they seek in gambling. In contrast, online players reported playing longer; it appeared to us that their feelings of being in control may contribute to this longer play and playing past a reasonable stopping point. The online gamblers we spoke with believed that they could somehow control the outcome better than those gamblers in a casino or themselves in a casino. Given the amounts of both time and money our online participants claim to spend on gambling, it is not apparent to us that they do have more control in the home setting. Early in her interview, Cleo explicitly claimed, as had other online gamblers, that she has more control playing online.

I just think I play better online than I do in person, 'cause I kinda get too excited in person. I' $m$ not really thinking and laying down the hand I should lay down. I chase the bad hands too much in person 'cause I get too caught up in it. But online I can be a little more detached and fold when I should fold. . . . I can just think a little more online than in person, so I make better decisions so I can beat people. (Cleo, 50 , online)

Later, however, in her interview, Cleo contradicted this account, recalling an online experience where she chased her losses: 
I lost four tournaments last night. . . . But after losing the first three, I figured, “Okay well, it just wasn't my night for the ring games." So I went to a heads up tournament where it's just two people, winner take all, which happens to cost five times as much as the other games. And I lost that one, too. So I took five times what I'd lost and lost it! I went to bed. It depressed me. I'm trying to quit smoking right now, and I went out and had two cigarettes and went to bed. (Cleo, 50 , online)

Indeed, although Cleo and others reported that they could focus more clearly and stay in control better by playing online, Cleo's quote highlights a double failure of control: imprudent gambling and smoking. Chasing losses is one sign of a potential gambling problem, and it is noteworthy that this strategy seems particularly easy to do online, with its easier and faster access to many tables and many games. We conclude that there exists among online gamblers a dangerous illusion of control over outcomes, monetary spending, and time commitment. The idea of control may have some positive aspects for the online players. But when that feeling of control goes too far-resulting in chasing losses or other undesirable behavior-it can be detrimental.

From Conviviality to Battle. The nature of the social contact during gambling changes the meaning of the game. For casino gamblers, social connections resulted in a convivial atmosphere in which gamblers spoke of interaction with others (both casino employees and other players) as part of their overall enjoyment. Casino gambling means conviviality. For online gamblers, the lack of physically present other people in their environment, coupled with their perceived anonymity, created a context where players were more aggressive, rude, and competitive. This led online gamblers to strategically avoid others, that is, to actively attach a battle meaning to gambling.

Connection with others is a fundamental human need, and our casino gamblers fulfill that convivial need by going to a casino where they can be around other people. Note that "being around people" did not mean forming long-term relationships but rather just enjoying being part of something larger than themselves. Fred mentioned a particular poignant time when he had a need to be around others and sought out the casino:

The night of 9/11, I went out because I was real depressed, this was a good time to be in a casino. . . . And I actually played some nickels at the Venetian, and I hit a jackpot of 150 bucks. I felt a little guilty. . . . I was gambling and our country has been attacked, but, it helped . . . being around people. . . . It's actually a good feeling for me. (Fred, 44, casino)

For Shelley, the casino allows her the benefit of being with people without having to get deeply involved in their lives. Talking about the people playing with her around the craps table, she says:
I don't have to make a judgment on them. They're just there, they're loud, they're great, they're having a great time. . . . I'll never see them again. Who cares. They don't affect my life at all, so I get my people rush without the commitment. (Shelley, 32, casino)

Herb talks to players around him on the slot machines, telling jokes or making small talk, and he says that slot participants will often "high five" each other if either gets a big win, even when both are strangers. Kristine told us that she does not like to sit by herself playing slot machines in the casino, so she will find someone to play beside. Like Herb, Kristine gets caught up in the convivial atmosphere. She often stays in the casino even after her money runs out, and she feels enjoyment when others win:

And it's a social occasion for people. . . . I like it when we
sit together, next to each other, and play. I do see people I
recognize. . . I do enjoy looking at the other people playing
and seeing how they're doing. You know, I mean I don't
have to be playing my own money. I get happy if, you know,
I'm watching somebody that hits the Wheel of Fortune. . .
You know, it's just as much fun for me if somebody else
wins. (Kristine, 57, casino)

The casino players enjoyed feelings of familiarity (like recognizing other people or being recognized by a server with their favorite drink), and they were satisfied with these more superficial social interactions. Sam refers to these interactions as an important part of the excitement of casino gambling (and something that would be missing for him if he moved online). Although in Las Vegas the games that he plays can also be accessed at gas stations or grocery stores, these locations lack the conviviality he desires:

I don't like going to get gas and start playing those machines. I don't like that. I like going to the casino. . . . . All the people around, out. It's more exciting. You can yell and stuff. . . . They root, you root each other on. (Sam, 32, casino)

Although online casinos attempt to recreate this conviviality through technological advances, for online participants, the meaning of gambling is more purely the game, the win, the battle. Indeed, online gamblers mainly tolerated some obtrusive technologies, like online chats, in order to focus on their battle, a strategy we call strategic ignoring. John notices the chat boxes but does not pay much attention to them because he considers himself more of a novice gambler who cannot concentrate both on the game and what people are chatting about. He notes that, if he were more experienced, perhaps he would strategically use those chats to avoid or target particular individuals, a strategy we elaborate on below. Similarly, Jessica turns off the chat boxes while playing because she would rather not have that type of interaction. (Recall that Jessica stopped going to casinos when online gambling became available so that she could avoid talking to others.) She posts the minimal amount of information about herself required by the casino site (name 
and age), but she refuses to post pictures or any personal information about herself, claiming she would prefer 15 hours of "not saying a word" to any type of interaction.

When I'm online I want to be as anonymous as possible. I don't want to hear from these people. I don't want them calling me, or sending me an e-mail. (Jessica, 54, online)

When Mike is in the middle of a challenging game, he has learned to avoid the chat boxes:

In fact you know when I'm up and down and up and down like that I don't chat. . . . You know I just focus on the game, that's all. So people will be trying to talk to me, and I just ignore them and their swearing at me. . . Doesn't bother me anymore. (Mike, 55, online)

Mike says that, when things are quieter and he is getting bored, he might notice and participate in the chat, but he will not let those kinds of interactions interrupt his focus on gambling.

A more active approach to these social connection technologies is the use of friends. Some online participants mentioned prearranged meetings with friends in certain tournaments or games and looking for virtual tables where they saw familiar, friendly avatars/icons. Unfortunately, situations where online gambling produces bullies or enemies were more prevalent. When Donna first started online gambling, she participated in the chat boxes, but an early chat interaction resulted in her being stalked (over the phone); she is now much more socially reclusive during online gambling. She relies on her cousin to scout out gambling sites for her, and she often seeks him in online games. In her interview, she referred to being in a "room full of sharks" when playing poker online, and she talked about being bullied in the online world:

When I clicked off, I was crying, I was at the point of tears. . . . I let a complete stranger who was online, didn't know me, I didn't know them, hurt me. If it was in person, it would be different. In person, at a table, it's just player 1 or player 2. (Donna, 53, online)

Donna has since learned to ignore the online chats and to focus on her own gambling. Tiffany also has a more fearful approach to her online contact. Although she has access to the computer all day, the only time that she ventures online to gamble is when her husband is with her to "protect" her. One of the reasons that Tiffany stopped gambling in a casino was her fear of others trying to steal from her, but her online behavior indicates that she is also fearful of others online.

The unregulated online environment results in a more chaotic environment with no clear social norms and rules. The meaning of gambling changes, moving from a sense of shared conviviality available in the casino to a no-holdsbarred battle online. Alice mentioned that there are several times that she has won a hand that someone at her table has called her a "bitch" in the chat area, something that would not be tolerated in the Vegas casino environment. Unlike Donna and Tiffany, whose responses to online bullies were to shy away, Alice says that such confrontation brings out her warrior spirit. For her (as well as others), the nasty people online brought out her competitive side. The first image Alice brought in was a picture of Sylvester fighting some bull dogs (see fig. 4). She relates her experience to the online bullies in relation to that picture:

That I like. Beating the other guy, especially. For example, there's this guy online that I can't stand. . . . He's a big bully and that's just what I call him. So when I see his icon I want to kick his ass. So [in the image] I am Sylvester confronting the big bully. So that's a challenge and whenever I do beat him, I feel great. (Alice, 58, online)

Manny also discussed how his perceived enemies online fueled his competitiveness. Indeed, the ability for the online battle to degrade into a more personal competition actually enhanced the positive experience of online gambling for both Alice and Manny.

Competition. It's me against these unknowns. And sometimes it gets to be, there's some nasty people playing. And their

FIGURE 4

ALICE'S SUMMARY IMAGE

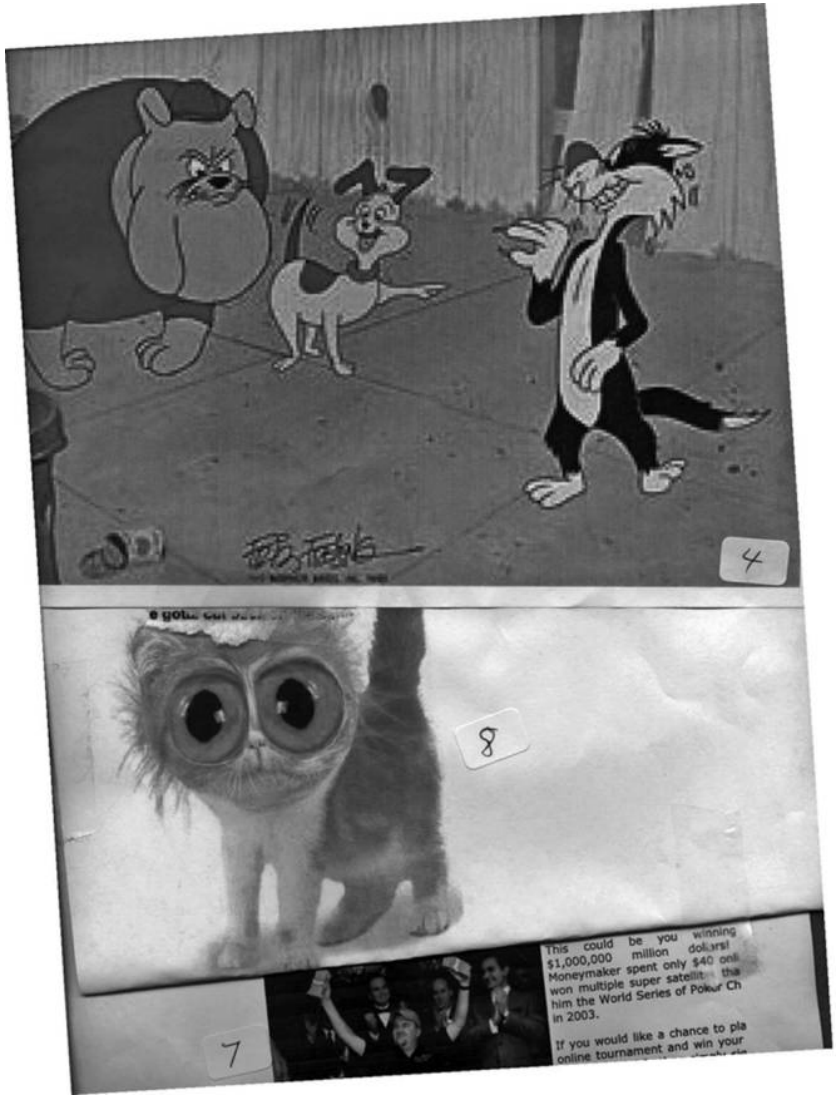


language is pretty foul at times. Especially if you beat them out of a couple of hands. And they can get pretty foul, their language, so it's kinda, it's kinda fun beating them. (Manny, 77 , online)

In conclusion, while the convivial atmosphere of the casino leads to positive, albeit superficial, social interaction, the online environment leads to a battling atmosphere that brings out gamblers' more competitive sides. Some approach this battle by learning to strategically avoid others or by having another person fight the battle for them. Others take on these unknown others and thrive through the battle. The online context has changed gambling's meaning from an activity where social togetherness is treasured to a social environment seen as a battleground. The lack of the civilizing social processes of the casino has helped to fuel excessively personal battles in the online realm.

From Separation to Integration. Casino gambling is considered a separation, a foray into a different world from the outside world. Even among regular casino gamblers, those who may play weekly or more often, there is a demarcation of going to the casino that simply is not the same as going online. In contrast, gambling online does not imply a separation; rather it is often fully integrated into day-today life. We will explore the separateness of casino gambling and juxtapose that to the integration of online gambling into everyday family and routine activities.

Melanie, a casino gambler who favors slot machines, said that she tried online gambling and that it quickly lost her interest. It simply was not enjoyable to have gambling integrated into real life. For her, going to a casino is about the total experience, a different world, and she discusses the Strip's opulence, glamour, and music. Similarly, Kristine describes this casino world:

You can be entertained and have all the elegance of people in a country club, and it doesn't cost anything. . . . Casinos are so beautiful. . . . An ordinary person can live like some wealthy person belonging to a private club. . . . You get to escape the treadmill of your life and get treated like royalty. (Kristine, 57, casino)

The separation of leaving normal life and entering casino life is also a necessary transition to the gambling experience for Herb. He is a very frequent gambler. When asked about whether he would consider online gambling, he first said that he did not see the point, but eventually he admitted that the idea of integrating gambling into his home created a fear that he could become addicted to online gambling. Herb repeatedly mentioned having to have discipline, a good balance between gambling and the rest of his life, and not becoming a victim of gambling. For him, creating a separation between real life and casino life was a critical component, where "walking through the casino door" allowed him a separate place for his gambling:

But I don't relate to [casino] gambling in the same way [as online], because. . . the second you walk past the door, you are in a new world. Be it a fantasy land with a castle or, you know, an old western town. (Herb, 42, casino)

Belinda, another casino gambler, also indicated that there are some days of the week when gambling is acceptable (on the weekends) and some when it is not (weekdays). She and her husband go out for dinner on the weekends, and they usually find their way to a casino. Recently, Belinda had a friend visiting from out of town, and she recalled the following:

I picked her up and I took her to the Venetian for breakfast. .. . We both sat down at a video poker machine next to each other, and I won ten dollars and got up and said, "Let's go." And she was okay with leaving. . . . I just felt guilty. It was during the week. It was like, I shouldn't be playing. You know, at all. . . . I think during the week, and the fact that it wasn't my night out, it was just kind of like, you know, I'm busy working with our business, and I run the whole office and do everything. . . . Losing eighty dollars on a Wednesday in the middle of the morning is, that would've really pissed me off. (Belinda, 42, casino)

In contrast to the separation of gambling from real life enjoyed - and needed-by our casino gamblers, the online gamblers relished the integration of online gaming into the home, which made it easier for gamblers to gamble without changing their current routine. Online gambling is quicker to both start and stop. Pacewise, a gambler can multitask, stop playing to make dinner for her family or do a load of laundry or take a phone call and then be right back to gambling quickly. Brittany remarks on how this integration makes her life easier:

Yeah, this [picture] is just family, because I've been thinking about my family. It's pretty good, when you can sit there and gamble [with them] and cooking and cleaning and go back and forth. (Brittany, 23, online)

With online gambling, there is no delay of the drive to a casino. Once gambling at a casino table, one must stay at a table until the gambling is finished. Online gamblers, in contrast, enjoy instant on/off and pausing, and they can jump tables if they desire. Donna, a former frequent casino gambler, discusses some of the benefits of this integration into her home:

It's convenient. . . . You can watch TV at the same time, listen to the radio. . . . At the casino, you have to get up. To use the bathroom here, you just put BRB, be right back. . . . There's this place where you just click so you don't lose your seat. (Donna, 53, online)

While the convenience of integrating gambling into home life was remarked on by all our participants, some of the potential downfalls of this integration were not. Manny, a retiree who used to visit the casinos frequently before his 
wife passed away, now finds himself spending more and more time gambling online. He mentions how the online environment is not as structured as the casino because he can walk to the fridge, get something to eat, and come back and join a game, and an advantage of playing poker online is that you can table jump, whereas in the casino there are a limited number of tables and wait time is usually high. One of the images of casinos he brought was a picture titled "Reason for Getting out of the Home." Casinos provided him with a social environment that had been separate from his daily activity. He now relies on the convenience of online gambling, losing the external social circle that he built in the casino.

Integration appears to have additional risks, and these were not always recognized by our participants. Mike admitted that he now plays online every night after dinner, while his wife is watching TV in the other room (gambling $\$ 500-\$ 1,000$ per evening). He mainly gambles online out of boredom "to pass the time." Mike brought in an image of a lightning bolt to represent the quickness of being online (see fig. 3). He also commented about the potential downfall of the increased pace of online gambling, as compared to the casino, when integrated with other home activities:

This is a train wreck, which happens. You can be playing along and you're doing well and all of a sudden if you're not focused or . . . I don't say I'm multitasking or anything, but I mean a lot of times, you know, I'll be doing two things and, you know, paying attention to her [wife] or TV and playing and sometimes for a lot of money and I just lose focus and the next thing I know like I've got a lot of money on the table and all of a sudden, you know, the gambling is going down . . . [snapping fingers] . . . it picks up. (Mike, 55 , online)

Another potential pitfall of the change in gambling meaning, from separation to integration into the home, has to do with exposing children to gambling. Brittany commented that the online environment was much better for her than the casino because she could share her experience with her 4-year-old daughter (see fig. 1). However, at-home gambling diverts attention and focus from other parental activities with the child. For example, Brittany stated that, if she were not gambling on the computer, she would be doing other activities with her child.

Exposure to gambling per se as a child might not be a negative, though some researchers argue that early exposure may lead to later gambling problems (Kallick et al. 1979). In memories and remembrances, gambling with parents was recalled fondly. For example, many participants spoke of seeing their parents play poker around the dining room table. These games were part of the family experience, and they were seen as being highly social, an extension of other types of game playing. Our online participants also talked about sharing online gambling with their children and partners as part of family time. But this is not the same as playing poker around the table with one's parents once one is old enough to understand the rules. Parents do not talk about engaging with their children via gambling but rather of integrating gambling time into family time; it is introducing gambling into your family rather than introducing your family to gambling, and this seems to us to be an important difference. For example, Brittany primarily gambles in the afternoon when her husband and 4-year-old are present, and she sees this as her family time.

And here [at home] if I win something big, I can experience it with my daughter. "Mommy won!" "Mommy just won!" At a casino, she wouldn't be able to sit there and have that kind of enjoyment with me. . . . She gets to clap. . . . I don't think she understands what I'm doing, but she gets excited when she hears the noise on the computer. Because it will make a noise, "You won!" or something like that. So she'll start jumping up and down too. (Brittany, 23, online)

Integrating gambling into the home often means more time spent together as a family because one or both parents are not away at the casino. Indeed, our casino players remarked that they enjoyed the separation of casino gambling in order to disconnect from their kids, the physical separation of casino gambling providing a break from family. For example, Belinda said that one thing she relished about going to the casino was leaving her children and responsibilities behind.

Delving further into the meaning of online gambling as consumption integrated into day-to-day life, we observe that there is a fine line between integrating online gambling into one's routine and having that routine turn into compulsion. Compulsion refers to "repetitive and purposeful behaviors that are performed according to certain rules or in a stereotyped fashion" (American Psychiatric Association 1985, 234). The in-home integration of online gambling certainly allows it to easily become a consumer compulsion, where day-to-day activities are driven by their gambling play. Indeed, several online players structured their daily activities around various tournaments (while we acknowledge that visiting casinos can also become ritualized, the in-home experience of online gambling makes the ritual easier to adopt). Alice plays several online poker tournaments each day, beginning at 8:00 in the morning. Her household chores, including making dinner, are scheduled around these four daily tournaments:

I don't play after seven o'clock at night, so I start at 8 o'clock, 10 o'clock, 1 o'clock and 4 o'clock. . . . By the time [husband] gets home, his dinner is always ready . . . but I'm still going back and forth between the computer and him; whatever he has to do in the evenings is cool because, like I said, by 6:30 I'm through. I don't even register for the 7 o'clock because enough is enough. (Alice, 58 , online)

Similarly, Donna explains that online gambling has become integrated into her evening routine.

[Each evening] I can indulge in my favorite game and I can sit with some ice cream and hot tea, and at that point I just 
don't care if I win or lose. [Later] Sometimes I'll get on and I'll be tired, but . . I I get online to kind of zone me out, package me away, forget about my pain, let the sleeping pill kick in. (Donna, 53, online)

\section{DISCUSSION}

In the last few decades, in North America the consumption of gambling and the attitudes toward it have undergone a remarkable transformation. Legalized casino gambling is widely accessible to virtually every North American consumer. The combination of increased access and increased cultural acceptance has led to increased gambling, both recreational and pathological. Casino gambling is heavily regulated and scrutinized. As a result, the experience of casino gambling is often more sanitized than the experience of illegal, unregulated online gambling. We know that transgression has appeal, whether it is based on sex, gambling, or other vices (Belk et al. 2003). Speculating somewhat, we believe that online gambling has more of a whiff of scandal and transgression, and so it may be more desirable to gamblers who can easily choose between casino and online (Smith 1996).

The ability to partake in online gambling is a result of technological advances in the Internet, in gambling software, and in secure payment systems. This technological system is clearly subject to the same sorts of technology paradoxes identified by Mick and Fournier (1998). In particular, we see four of the paradoxes they identify as particularly salient to in-home consumption of gambling: freedom/enslavement, efficiency/inefficiency, assimilation/isolation, and engaging/ disengaging. First, online gamblers face fewer restrictions (including prohibitions on ages appropriate for gambling) and yet these reduced restrictions, for some people, lead to a dependence on the technology, as we have seen (freedom/ enslavement). Second, online gambling means that the time required to get into a gambling consumption situation is far less (click of a mouse versus the trip to a casino). However, this technology also appears to result in far more absolute time spent gambling (efficiency/inefficiency). Third, when online gamblers integrate their families in gambling, particularly their children, they are facilitating some family togetherness. However, online gambling, particularly for some seniors, meant that they did not venture out to the casino anymore, reducing their social interactions (assimilation/isolation). Finally, we saw evidence of online gambling certainly creating flow experiences but simultaneously leading to a more passive consumption of gambling games (engaging/disengaging).

When gambling consumption moves into the home, gambling behavior becomes a part of everyday living. When not seen as reserved solely as behavior for an outing or a special occasion, we found that gambling is more likely to become a pernicious, insidiously integrated component of a consumer's life. Online gambling can happen without the knowledge of nongambling significant others (spouse, par- ents). It can be done away from their gaze and their censure. One can also sneak out to a casino too, but it is harder to hide this behavior, and it should be impossible for children or adolescents to enter a casino.

The next generation of gamblers is the first in modern history to grow up in an era when gambling is legally sanctioned and at least somewhat culturally approved of. Unfortunately, adolescents have proven extremely susceptible to the enticements of gambling; past research has found that they become addicted gamblers at rates even greater than their adult counterparts. A meta-analysis of gambling studies in North America led the researchers to conclude that the rate of problem gambling for youths ranged between $9.9 \%$ and $14.2 \%$, while an additional $4.4 \%-7.4 \%$ were already exhibiting compulsive gambling behaviors (Shaffer and Hall 1996). Because the Internet allows even more accessibility to underage gamblers and the integration of the gambling experience into everyday life heightens its cultural acceptability, it is likely that the problems with adolescent gambling will become even greater. Indeed, the number of college males who gambled online at least once a week had quadrupled between 2005 and 2006; overall, estimates are that 1.6 million U.S. college students gambled online during the same time period (Woodruff and Gregory 2005). It is estimated that, of these, one quarter of them exhibited the characteristics of a pathological gambler (D. Schwartz 2006).

An important aspect of this movement of formerly public consumption experiences into the home is the reduction in regulation. There is little or no ability to police these illegal sites and no strict, enforceable regulations. Among the online gamblers we spoke with, there is a widespread belief that underage players are gambling online, and several online participants told us about fellow gamblers soliciting help for their homework via the gambling chat boxes. This is perceived by our participants as a negative aspect of online gambling; several participants believe that online access to youth will lead to increased gambling addictions. Regardless of whether one believes in intervention to protect consumers from themselves or one takes a more libertarian view, there is no escaping the conclusion that, with online gambling, there are little or no protections for the populations that would be banned in casinos (e.g., children).

As access to gambling increases, so too does the potential for the absolute number of problem gamblers to grow. Indeed the illegal (and as a result unregulated) online gambling Web sites continue to multiply, enticing more and more consumers to move gambling into the home. There are several frightening consumer welfare implications of this. First, intergenerational influence will lead to gamblers who grow up seeing nothing unusual in wagering relatively large sums of money from one's home. We know that many varied consumption behaviors and consumption values are transmitted intergenerationally (Moore, Wilkie, and Lutz 2002). Recent research has also shown that early exposure can imprint later preferences (Braun-LaTour, LaTour, and Zinkhan 2007). More than half our sample mentioned learning to gamble from someone in their family. For these people, 
there is a positive, nostalgic glow to gambling. There are indications that this will continue to be passed to their children.

Second, gambling, as an integrated feature of the home, becomes a routinized part of everyday consumption (like watching television), and that sort of routine can lead to more mindless consumption of gambling and resultant losses. That is because, in contrast to a separated gambling consumption event with predetermined attempts at setting a limited budget (regardless of success at budgeting), in-home consumption becomes something explicitly not planned for, something that is just done every day.

Oddly enough, one potential solution for many of these problems is allowing legitimate (corporate) sponsors of gambling, like the corporations who run the major casinos in Las Vegas (or even the government sponsors in Canada), to enter a newly regulated market for online gambling. Just as legalized commercial gambling in casinos allowed governments to regulate it, so too could the legalization of online gambling allow for better regulation and for attempts at reducing the growth of problem gamblers.

We demonstrated that there are many ways to consume online gambling. It can involve reasonably healthy and somewhat social interaction online, with the use of chat rooms and virtual pictures at a poker table. It can also be done alone, resulting in the solitary, routine loss of money in everyday gambling at home. There are ways that online casinos could reduce the harmful effects of gambling. These include better age checks associated with signing up for an online account, cross-checking new users with lists of pathological gamblers, setting financial limits on gambling, having the site communicate to gamblers who are spending long hours and a lot of money, and relaying information about problem gambling treatments via pop-ups or instant messages. Regulations might also require having a problem gambling counselor available online.

Another one of our prescriptions for a new, heavily regulated online gambling industry is a cooling off period. Rarely used by online gambling sites currently, this technique forces gamblers to stop gambling for some preset amount of time before they are allowed to remove more money from their accounts; that is, there is a delay between when they request more money and when they are allowed to access it. Additionally, the online provider could make the tabulations of wins and losses more central and larger on the screen to increase the player's awareness of where they stand. This might mitigate the behavior that we observed in our data: emotional detachment from the online game resulted in large losses.

One of the more positive aspects of our results regarding online gambling is that the online atmosphere does not provide many of the emotional highs associated with being in a regular casino. As long as the online environment remains of rather low intensity as an emotional experience, without the social connection and "fire of desire" fueled by the casino environment, the propensity for addiction might not necessarily be as strong. The online environment is also lacking in sensory touch stimulation. Peck and Childers (2006) find that the salience of touch increases impulse-purchasing behavior, suggesting that consumers in casinos may be more prone to making impulsive decisions than their online counterparts.

However, one can easily see how the online casino provider could make the online game more exciting-flashing bold graphics on screen with a big win or allowing more signs of status (such as multiple dollar signs next to screen names, differentiating experts from novice gamblers) in order to feed into the ego and achievement aspect of the traditional casino. Although this is somewhat speculative, based on our data, we believe that, if these were incorporated into the online experience, it would likely increase the problematic possibility of online gambling.

In our sample, the online gamblers were able to supplement their gambling in a casino. This speaks to one of the limitations of our sample, as there are many online gamblers who do not have such easy access to casinos. Also, our participants were first exposed to gambling through casinos and later went online; casinos framed how they approached online gambling.

The myth of easy money continues to fuel gambling consumption, and the online, in-home consumption of gambling has far more pernicious effects, as we have shown. Gambling is only one of several forms of dark-side consumption behaviors that negatively affect many consumers. Whatever one's political or moral stance on gambling, or of other darkside behaviors, we all at least need to consider that, with online access being increasingly available in every home, we (and our children) will need to deal with casinos in every home (King 1999).

\section{REFERENCES}

American Gaming Association (2004), 2004 State of the States: The AGA Survey of Casino Entertainment, Washington, DC: American Gaming Association.

American Psychiatric Association (1985), Diagnostic and Statistical Manual of Mental Disorders, Washington, DC: American Psychiatric Association.

Associated Press (2006), "Global Gambling Revenues Expected to Rise,” June 21, http://www.encyclopedia.com/doc/1P1-125462540 .html.

Belk, Russell W., Guliz Ger, and Soren Askegaard (2003), "The Fire of Desire: A Multisited Inquiry into Consumer Passion," Journal of Consumer Research, 30 (December), 326-51.

$\rightarrow$ Braun-LaTour, Kathryn A., Michael S. LaTour, and George M. Zinkhan (2007), "Using Childhood Memories to Gain Insight into Brand Meaning," Journal of Marketing, 71 (April), 45-60.

$\rightarrow$ Christensen, Glenn L. and Jerry C. Olson (2002), "Using the Zaltman Metaphor Elicitation Technique (ZMET) to Map Consumers' Mental Models," Psychology and Marketing, 19 (June), 477-502.

Cotte, June (1997), "Chances, Trances, and Lots of Slots: Gambling Motives and Consumption Experiences," Journal of Leisure Research, 29 (4), 380-406.

Coulter, Robin and Gerald Zaltman (2000), "The Power of Metaphor," in The Why of Consumption: Contemporary Perspectives 
on Consumers Motives, Goals and Desires, ed. S. Ratneshwar, David Glen Mick, and Cynthia Huffman, London: Routledge, 259-81.

Damasio, Antonio R. (1994), Descartes' Error: Emotion, Reason, and the Human Brain, New York: Putnam.

$\rightarrow$ Derevensky, Jeffrey L. and Rina Gupta (2007), "Internet Gambling amongst Adolescents: A Growing Concern," International Journal of Mental Health and Addictions, 5 (2), 93-101.

$\rightarrow$ Fisher, Sue (1993), "The Pull of the Fruit Machine: A Sociological Typology of Young Players," Sociological Review, 41 (August), 446-74.

$\rightarrow$ Flaherty, Lisa M., Kevin J. Pearce, and Rebecca Rubin (1998), "Internet and Face-to-Face Communication: Not Functional Alternatives," Communication Quarterly, 46 (3), 250-68.

Griffiths, Mark D. (2002), "The Biopsychosocial Approach to Gambling: Contextual Factors in Research and Clinical Interventions," Electronic Journal of Gambling Issues, 5, http://www .camh.net/egambling.

Grinols, Earl L. (2004), Gambling in America: Costs and Benefits, Cambridge: Cambridge University Press.

Herman, Robert D. (1976), Gamblers and Gambling, Lexington, MA: Lexington Books.

$\rightarrow$ Hirschman, Elizabeth C. (1992), "The Consciousness of Addiction: Toward a General Theory of Compulsive Consumption," Journal of Consumer Research, 19 (September), 155-79.

$\rightarrow$ Hornik, Jacob (1992), "Tactile Stimulation and Consumer Response," Journal of Consumer Research, 19 (December), 449-58.

Kallick, Maureen, Daniel Suits, Teddy Dielman, and Judith Hybels (1979), A Survey of American Gambling Attitudes and Behavior, Research Report Series, Survey Research Center, Institute for Social Research, Ann Arbor: University of Michigan Press.

$\rightarrow$ King, Storm A. (1999), "Internet Gambling and Pornography: Illustrative Examples of the Psychological Consequences of Communication Anarchy," Cyberpsychology and Behavior, 2 (3), 175-93.

$\rightarrow$ King, Storm A. and Azy Barak (1999), "Compulsive Internet Gambling: A New Form of an Old Clinical Pathology," CyberPsychology and Behavior, 2 (5), 441-56.

$\rightarrow$ Ladd, George T. and Nancy M. Petry (2002), "Disordered Gambling among University-Based Medical and Dental Patients: A Focus on Internet Gambling," Psychology of Addictive Behaviors, 16 (1), 76-79.

Lakoff, George and Mark Johnson (1980), Metaphors We Live By, Chicago: University of Chicago Press.

$\rightarrow$ Loroz, Peggy Sue (2004), "Golden-Age Gambling: Psychological Benefits and Self-Concept Dynamics in Aging Consumers' Consumption Experiences," Psychology and Marketing, 21 (5), 323-49.

$\rightarrow$ Mantovani, Giuseppe (2001), "The Psychological Construction of the Internet: From Information Foraging to Social Gathering to Cultural Mediation," Cyberpsychology and Behavior, 4 (1), $47-56$.

$\rightarrow$ McKenna, Katelyn Y. A. and John A. Bargh (2000), "Plan 9 from Cyberspace: The Implications of the Internet for Personality and Social Psychology," Personality and Social Psychology Review, 4 (1), 57-75.

$\rightarrow$ Mick, David Glen and Susan Fournier (1998), "Paradoxes of Technology: Consumer Cognizance, Emotions, and Coping Strategies," Journal of Consumer Research, 25 (September), 123-43.

$\rightarrow$ Moon, Youngme (2000), "Intimate Exchanges: Using Computers to Elicit Self-Disclosure from Consumers," Journal of Consumer Research, 26 (March), 323-36. $\rightarrow$ Moore, Elizabeth S., William L. Wilkie, and Richard J. Lutz (2002), "Passing the Torch: Intergenerational Influence as a Source of Brand Equity," Journal of Marketing, 66 (April), 17-37.

$\rightarrow$ O'Guinn, Thomas C. and Ronald J. Faber (1989), "Compulsive Buying: A Phenomenological Exploration," Journal of Consumer Research, 16 (September), 147-57.

$\rightarrow$ Peck, Joann and Terry L. Childers (2006), "If I Touch It I Have to Have It: Individual and Environmental Influences on Impulse Purchasing," Journal of Business Research, 59 (June), 765-69.

$\rightarrow$ Schau, Jensen Hope and Mary C. Gilly (2003), "We Are What We Post? Self-Presentation in Personal Web Space," Journal of Consumer Research, 30 (December), 385-404.

Schwartz, David G. (2006), Roll the Bones: The History of Gambling, New York: Gotham.

Schwartz, Mattathias (2006), "The Hold-'Em Holdup," New York Times Magazine, June 11, http://www.nytimes.com/2006/06/ $11 /$ magazine/11poker.html.

$\rightarrow$ Shaffer, Howard J. and Matthew N. Hall (1996), "Estimating the Prevalence of Adolescent Gambling Disorders: A Quantitative Synthesis and Guide toward Standard Gambling Nomenclature," Journal of Gambling Studies, 12 (Summer), 193-214.

$\rightarrow$ Shaffer, Howard J. and Rachel Kidman (2003), "Shifting Perspectives on Gambling and Addiction," Journal of Gambling Studies, 19 (March), 1-6.

$\rightarrow$ Smith, Alan D. (2004), "Controversial and Emerging Issues Associated with Cybergambling (e-Casinos)," Online Information Review, 28 (6), 435-43.

Smith, James F. (1996), "When It's Bad It's Better: Conflicting Images of Gambling in American Culture," in Gambling Cultures: Studies in History and Interpretation, ed. Jan McMillen, London: Routledge, 101-15.

Spears, Russell and Martin Lea (1992), "Social Influence and the Influence of the 'Social' in Computer-Mediated Communication," in Contexts of Computer-Mediated Communication, ed. Martin Lee, Hemel Hempstead: Harvester Wheatsheaf, 30-65.

$\rightarrow$ Spiggle, Susan (1994), "Analysis and Interpretation of Qualitative Data in Consumer Research," Journal of Consumer Research, 21 (December), 491-503.

$\rightarrow$ Sproull, Lee and Sara Kiesler (1986), "Reducing Social Context Cues: Electronic Organizational Communication," Management Science, 32 (11), 1492-1512.

$\rightarrow$ Straus, Susan G. (1997), "Technology, Group Process, and Group Outcomes: Testing the Connection in Computer-Meditated and Face-to-Face Groups," Human Computer Interaction, 12 (3), 227-66.

Stutz, Howard (2005), “Easy Money, Easier Addiction?” Las Vegas Review-Journal, October 9, http://www.reviewjournal.com/ lvrj_home/2005/Oct-09-Sun-2005/news/3508264.html.

$\rightarrow$ Thompson, Craig J. (1997), "Interpreting Consumers: A Hermeneutical Framework for Deriving Marketing Insights from the Texts of Consumers' Consumption Stories," Journal of Marketing Research, 34 (November), 438-55.

$\rightarrow$ Thompson, Craig J., William B. Locander, and Howard R. Pollio (1990), "The Lived Meaning of Free Choice: An ExistentialPhenomenological Description of Everyday Consumer Experiences of Contemporary Married Women," Journal of Consumer Research, 17 (December), 346-61.

Walker, Michael B. (1992), "A Sociocognitive Theory of Gambling Involvement," in Gambling and Commercial Gaming: Essays in Business, Economics, Philosophy, and Science, ed. William R. Eadington and Judy A. Cornelius, Reno: University of Nevada, $371-98$ 
$\rightarrow$ Woodruff, Christopher and Susan Gregory (2005), "Profile of Internet Gamblers: Betting on the Future," UNLV Gaming Research and Review Journal, 9 (1), 1-13.

$\rightarrow$ Zaltman, Gerald (1997), "Rethinking Market Research: Putting People Back In," Journal of Marketing Research, 34 (November), 424-37.
Zaltman, Gerald and Robin Coulter (1995), "Seeing the Voice of the Customer: Metaphor-Based Advertising Research," Journal of Advertising Research, 35 (July/August), 35-51.

$\rightarrow$ Zola, Irving Kenneth (1963), "Observations on Gambling in a Lower Class Setting,” Social Problems, 10 (30), 353-61. 